\title{
Human Stress Management through Heart Rate Variability
}

\author{
Bukhari Shafiq Bin Asnain \\ Faculty of Information \& Technology, Multimedia University, Melaka, Malaysia \\ Email: bukhari.shafiq94@gmail.com \\ Siew-Chin Chong \\ Faculty of Information \& Technology, Multimedia University, Melaka, Malaysia \\ Email: chong.siew.chin@mmu.edu.my \\ Kuok-Kwee Wee \\ Faculty of Information \& Technology, Multimedia University, Melaka, Malaysia \\ Email: wee.kuok.kwee@mmu.edu.my
}

Received: 05 March 2018; Accepted: 22 June 2018; Published: 08 August 2018

\begin{abstract}
Nowadays, there are many people having stress issues. Most of them do not know how to handle stress properly which may cause harm to their health condition. Moreover, they also may not notice that they are having stress until it become worsen. As we know, a calming surrounding and environment helps in soothing the emotion of a stressed person. In this project, an Android mobile application named "Intelligent Stress Relief App" will be developed to minimize the problems above. This application allows user to check their stress level based on their heart rate data through Bluetooth heart rate sensor. With the records of stress patterns, user is able to keep track of their stress condition in order to seek for better stress management. Furthermore, this application will provide user with a database of meditation techniques and relaxing music to assist them in releasing their stress.
\end{abstract}

Index Terms - Heart rate, android, stress management, Bluetooth, sensor.

\section{INTRODUCTION}

In our current modern times, the pace of life is moving too fast, leaving us without time to sit down, relax and handle our accumulated life's pressures and pits. Mental stress can be further referred as an event where cognitive stressors causing a short term activation of the sympathetic nervous system. Human body is able to return to its normal state after dealing with stress under healthy conditions. However, the continuous exposure to stressful event may lead to chronic stress and exhaustion. Based on the statistic [1], there are 526,000 workers suffering from work-related stress, depression or anxiety in Year 2016/17. Many people do not aware that they are having stress issues and do not know how to manage them in a proper way. Once stress becomes serious, it may affect someone's mood, behavior and body. There is another survey "Malaysia's Healthiest Workplace by AIA Vitality Survey 2017" [2], which surveyed a total of 5,369 employees from 47 organizations, revealed that Malaysian employees were overworked, stressed, led unhealthy lifestyles, and as a result, were at high risk of health problems and loss of productivity. Stress can be dangerous if not treated well. Moreover, stress is the basic cause of $60 \%$ of all human illness and disease that includes heart disease, high blood pressure, stroke and diabetes [3]. This is why human stress management is important.

The proposed application, dubbed "Intelligent Stress Relief", is an application that may help people to manage and reduce own stress through a wearable Bluetooth heart rate sensor. The application allows user to check their stress level and understand their stress patterns using their heart rate data obtained from a Bluetooth heart rate sensor. Stress level can be calculated with just 2 minutes of heart beat interval. Stress level can be categorized based on Heart Rate Variability (HRV) triangular index through the user's heart rate data. HRV triangular index is calculated using the formula where the sum of Normalto-Normal (NN) heart rate interval is divided with maximum NN heart rate interval [4]. There are five levels of stress which includes highly tense, slightly tense, mildly calm, quietly relaxed and deeply relaxed, as shown in the Table 1.

This application provides three main features, which are stress level checker, stress management, and database of meditation technique and relaxing music. Checking user stress level can be done by using Bluetooth heart rate sensor. A Bluetooth heart rate sensor is commonly embedded inside a smart watch, jogging tracker and others. HRV triangular index is measured from the user's heart rate data through the reading of the heart rate sensor. Then the specific stress level of the user will be determined based on the HRV triangular index. 
Table 1. Category of Stress Level based on Heart Rate Variability (HRV)

\begin{tabular}{|c|c|}
\hline $\begin{array}{c}\text { Heart Rate Variability } \\
\text { Triangular Index }\end{array}$ & Stress Level \\
\hline $2-15$ & Highly Tense \\
\hline $16-25$ & Slightly Tense \\
\hline $26-52$ & Mildly Calm \\
\hline $53-60$ & Quietly Relaxed \\
\hline$>60$ & Deeply Relaxed \\
\hline
\end{tabular}

According to the stress level, different responses from the application will be provided to the users. For example, the application will automatically play relaxing music and meditation technique audio when user is detected with slightly tense and highly tense after checking their stress level. There is a need of a calming surrounding and relaxing environment for people who are in stress to reduce their stress. Relaxing music helps in creating a relaxing atmosphere that is very much needed by stressed people. Other than that, the combination of relaxing sound and meditation techniques can be another solution to handle stress issues. Besides, users are allowed to manually choose their preferred music and meditation technique from the list. This application is equipped with a database of relaxing music and meditation technique to be used by the user.

User's previous results of stress level are logged in online database using Google Firebase. This means user can retrieve and keep track of their stress patterns for better stress management. This in turn may trains users to take appropriate measures to manage stressful situations. Furthermore, user can set reminder notification to remind them to check their stress level regularly.

The details of this paper is elaborated and organized follows. In section II, some of the existing mobile apps related to the topic are briefly reviewed. Section III discusses the proposed system design. The implementation process of the proposed system is elaborated in Section IV. The testing scenario and result are tabled in Section V and finally, Section VI draws the concluding remarks of this paper.

\section{RELATED WORK}

People show more concern about their health than earlier and increase their expectation towards mobile applications in managing their health status. In addition, the increasing demands of various fitness devices such as smart watch and jogging trackers inevitably show the awareness of people towards their health. There are plenty of mobile applications either Android or Mac iOS related to stress management have been developed over the years in the market. Most of the applications work as a library of meditation tools and relaxing music. Some of them are equipped with heart rate tracking. There are very less applications that calculate stress level and provide suitable advice to reduce stress, as what the proposed application does. The proposed application that utilizes the wearable fitness devices for sensing heart rate data is another highlight of the idea, in which the portability and convenience towards user are promised.

Table II shows the comparison of existing applications in the market. The existing applications related to stress management often lack of certain features. The aims of the proposed mobile app are to provide a complete package of stress management in single mobile application and enhance the weaknesses of the existing mobile applications.

Table 2. Feature comparison of related existing mobile apps

\begin{tabular}{|c|c|c|c|c|c|c|}
\hline$\searrow$ & $\frac{\sqrt{n}}{\frac{\Xi}{\pi}}$ & 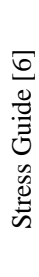 & 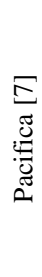 & 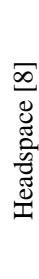 & 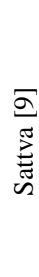 & 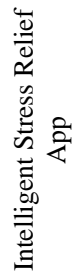 \\
\hline Guided meditations & $\checkmark$ & & $\checkmark$ & $\checkmark$ & $\checkmark$ & $\checkmark$ \\
\hline Relaxing music & $\checkmark$ & & $\checkmark$ & & & $\checkmark$ \\
\hline Progress tracking & $\checkmark$ & & $\checkmark$ & $\checkmark$ & $\checkmark$ & $\checkmark$ \\
\hline Reminder & $\checkmark$ & & $\checkmark$ & $\checkmark$ & & $\checkmark$ \\
\hline $\begin{array}{l}\text { Stress level checking } \\
\text { (based on heart rate) }\end{array}$ & & $\checkmark$ & & & & $\checkmark$ \\
\hline Heart rate monitor & & $\checkmark$ & & & $\checkmark$ & $\checkmark$ \\
\hline $\begin{array}{l}\text { Automatically play } \\
\text { relaxing music and } \\
\text { meditation technique } \\
\text { audio when user get a } \\
\text { bad stress level result }\end{array}$ & & & & & & $\checkmark$ \\
\hline
\end{tabular}

A comparison of the existing mobile applications that are available in the market and related to the proposed application, with a brief outline of their specification is listed below:

a. Calm [5]: This application offers a huge library of meditation technique and relaxing music. There is '7 Days of Calm' meditation program available right away after installing the app for free. One of the downside is that user need to pay subscription fee to use most of the content. Subscription costs USD 12.99 monthly, USD 59.99 yearly or USD 299.99 for a lifetime. It provides unique relaxing music to be play by user during their session. The relaxing music includes nature sounds like fireplace, foggy stream, rain on leaves and many more. The application also provides progress tracking and reminder to make sure that user is on track during their meditation journey.

b. Stress Guide [6]: This application allows user to check their stress level based on their heart rate. Heart rate data is obtained through user's device camera. However, it is not portable enough like taking reading from wrist heart rate sensor to keep 
track at all times. There is also heart rate monitor function that might come handy to some user. Based on the user's result, the app will give personalized tips on how to cope with stress.

c. Pacifica [7]: This application offers a huge library of meditation techniques and relaxing music but user need to pay for subscription fee in order to get full access. Subscription costs USD 5.99 monthly and USD 35.99 yearly. Free user still can benefit from the app despite limited access to the library but at some point the user might need the paid subscription. It also provides basic function such as progress tracking and reminder like other app in the market.

d. Headspace [8]: This application has a huge library that focus on meditation techniques. Same as [5,7], user will need to pay in order to get full access. Subscription costs USD 12.99 monthly and USD 94.99 yearly. There is level system for the app guided meditation course. Free user only get access to the first level which is not enough obviously. User definitely need the paid subscription in order to benefit from the app. It also provides progress tracking and reminder like other app in the market.

e. Sattva [9]: This application offers a library of meditation techniques and user only needs to pay a small amount in order to benefit from the app. User do not need to pay monthly or yearly subscription but instead they only pay for the guided meditation that they want and the best thing about it that they can keep them forever. Price starts from USD 0.99 for each guided meditation. However, the app is lack of relaxing music but developer add a function where user can play music from their phone's music library during meditation session to overcome the limitation. The application provides progress tracking and heart rate measuring through device camera for heart rate monitor purpose. It also provides feature like reminder to help user stay on the track throughout their journey using the app.

All the existing mobile applications mention above does not come with a complete package unlike the proposed mobile application. The proposed mobile application comes with all the important features like guided meditation, relaxing music, progress tracking, reminder, stress level checking and heart rate monitor. On top of that it also offers a unique feature that automatically play relaxing music and meditation technique audio whenever user is getting a bad stress level result. Not to mention that user can use all the features without paying a cent unlike the existing mobile applications.

\section{Proposed System DeSIGN}

The main goal of the proposed mobile application is to measure user's stress level based on heart rate data through a Bluetooth heart rate sensor and provide suitable advice according to the different levels of stress as listed in Table I in the previous section. In order to measure the stress level, user would need to install the proposed mobile application on his/her Android device and connect a Bluetooth heart rate sensor (smart watch, jogging trackers and others with heart rate sensor feature) with his/her Android device. The system architecture is shown in Fig. 1. The heart rate reading of a user is tracked through the heart rate sensor. Then the heart rate data is transmitted to the Android device with Bluetooth connection. The proposed application in the Android device will calculate the heart rate variability (HRV) triangular index using the heart rate data to determine the stress level. From the stress level, the proposed application will automatically play a particular music or meditation technique audio.

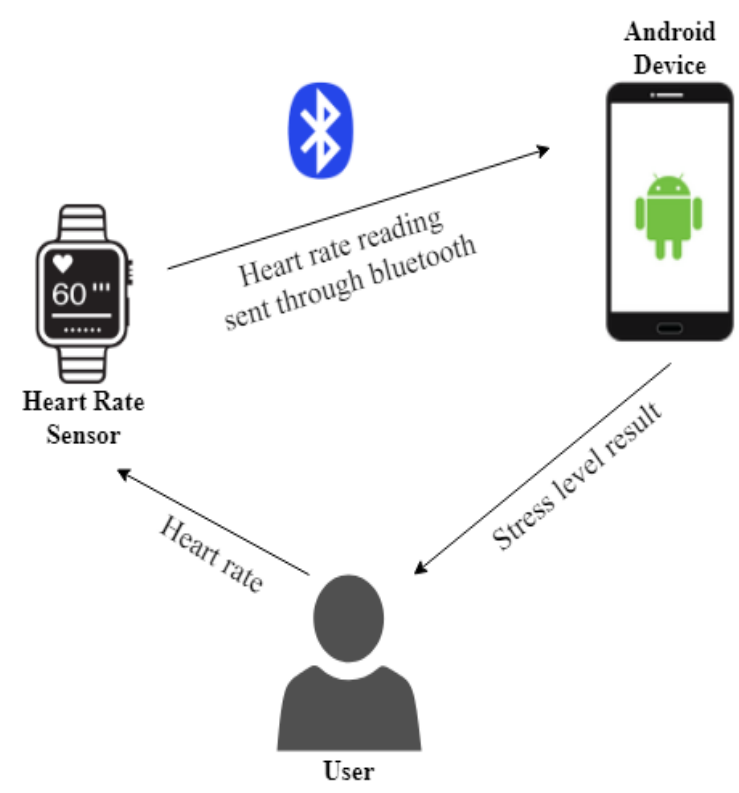

Fig.1. System architecture

Fig. 2 shows the flow chart diagram of the proposed mobile application. In this flow chart diagram, the process of transmitting and converting heart rate data to stress level is demonstrated. If the stress level is mildly calm, quietly relaxed or deeply relaxed, there is no advice being generated from the process and the process will end. For slightly tense stress level, the application will play relaxing music automatically and the process will end. Lastly, both the relaxing music and meditation audio will be played if the result is highly tense. After that the process will end. 


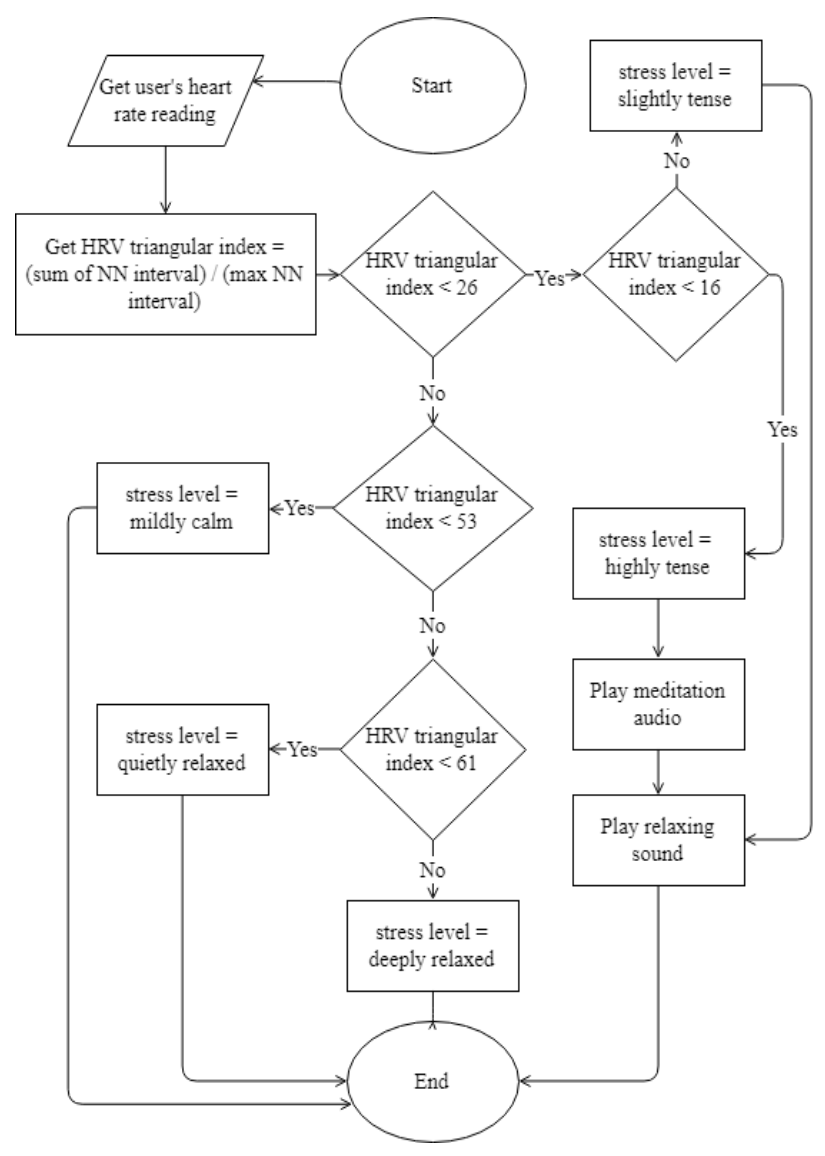

Fig.2. Flow chart diagram

\section{A. Application Scenarios}

Fig. 3 shows a scenario when user obtains highly tense as stress level result after checking their stress level using the application and a Bluetooth heart rate sensor. When the result is highly tense, there is an urge for user to reduce their stress seriously. Hence, the application will automatically play suitable relaxing music and meditation technique audio to calm the user. User is allowed to manually select the preferred music and meditation audio if there is a need.

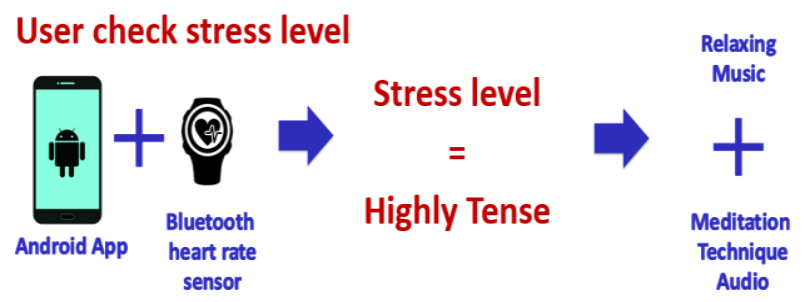

Fig.3. Highly tense stress level result

Fig. 4 shows a scenario when user receives slightly tense as stress level result after checking their stress level using the application and a Bluetooth heart rate sensor. Since the stress level is not high, the application will automatically play only the relaxing music to sooth user stress. Other than that, in a situation that user gets mildly calm, quietly relaxed or deeply relaxed as their stress level result, the application will not play relaxing music or meditation audio but it will give a praise due to the good result.

\section{User check stress level}

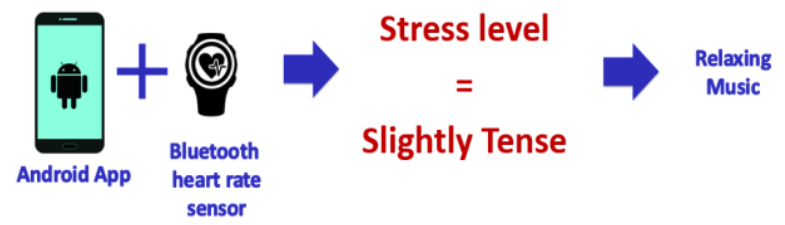

Fig.4.Slightly tense stress level result

\section{B. Important Source Codes}

The proposed application is tested and paired with $\mathrm{Mi}$ Band 2 Bluetooth heart rate sensor. In order to support Mi Band 2 Bluetooth heart rate sensor with the proposed mobile application, Mi Band SDK must be applied. Mi Band SDK dependencies and declaration need to be included in the coding in order to use Mi Band SDK. The code snippet used to connect $\mathrm{Mi}$ Band 2 with the proposed Android application is shown in Fig. 5.

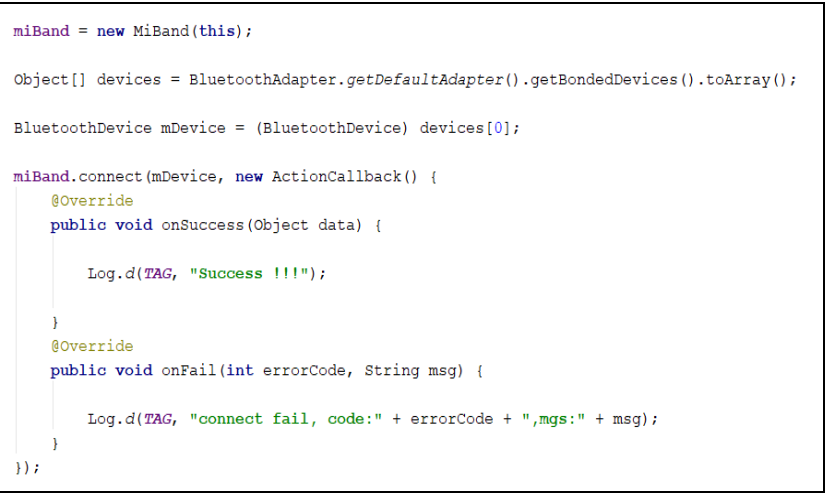

Fig.5. Connecting Mi Band 2 using Mi Band SDK

Fig. 6 demonstrates the snapshot of code to enable Mi Band 2 heart rate scan with its sensor. The sensor allows the scan to get started.

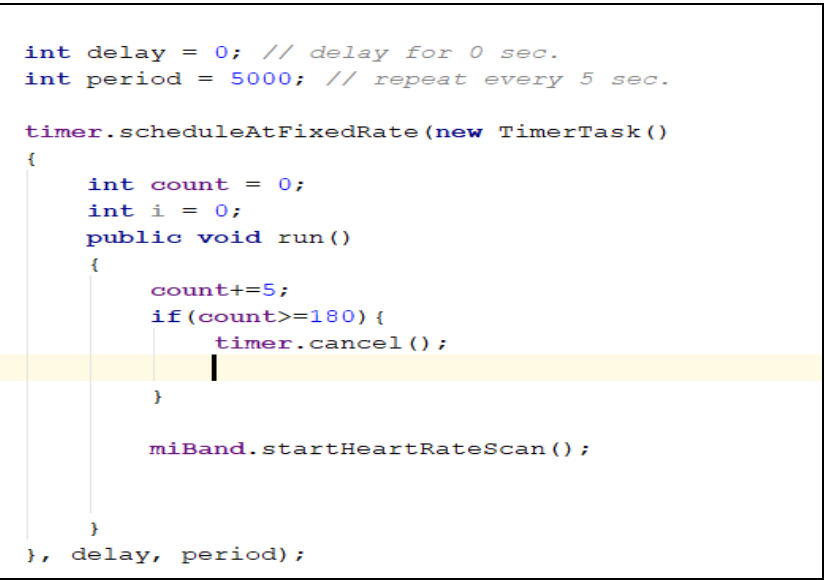

Fig.6. Enabling Mi Band 2 heart rate scan 
Fig. 7 shows, the code snippet used to extract heart rate data and measure stress level throughout the activity in the application.

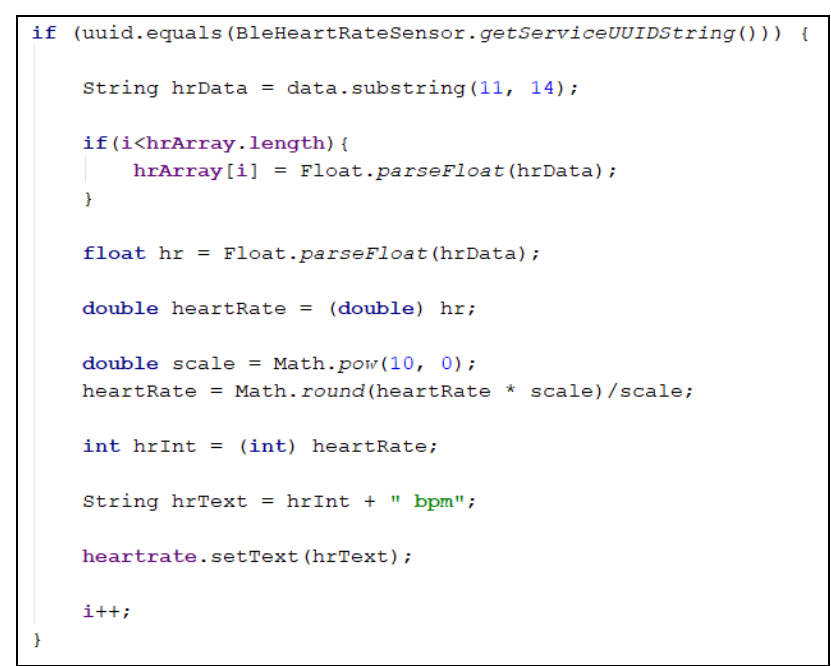

Fig.7. Extracting heart rate scan

Lastly, Fig. 8 presents the snapshot of code to calculate the heart rate Normal-to-Normal (NN) interval with the heart rate data extracted while Fig. 9 displays part of the code that is used to calculate and classify the HRV triangular index. The index determines the specific stress level of the user.

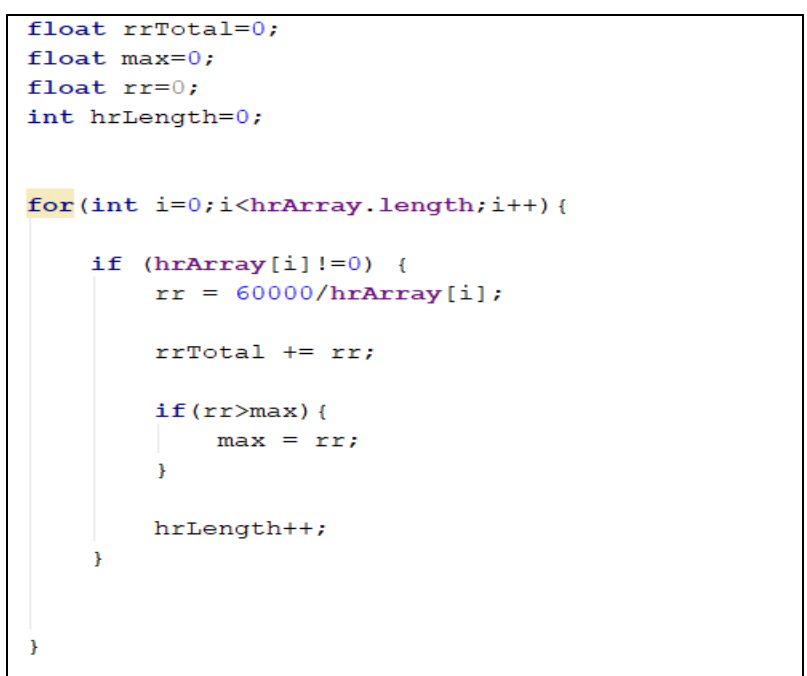

Fig.8. Heart rate NN interval calculation

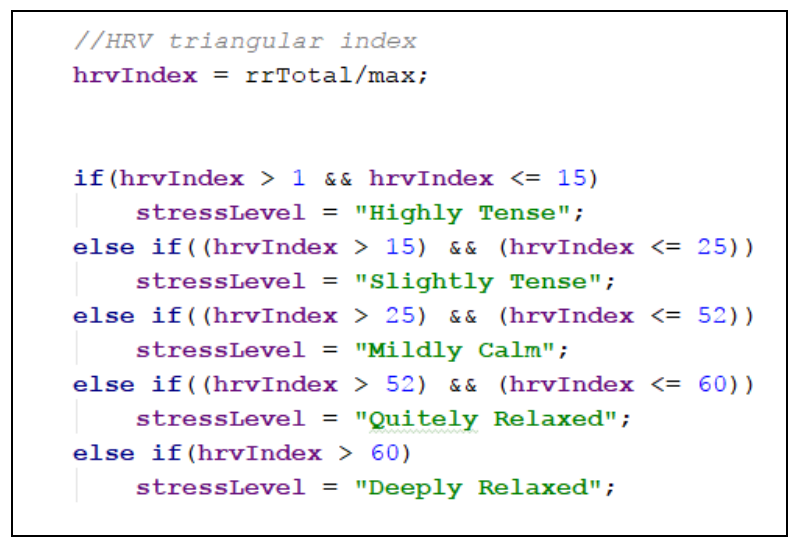

Fig.9. HRV triangular index calculation \& classification

\section{IMPLEMENTATION PROCESS}

The implementation process of the proposed application can be divided into two main tasks, which are developing prototype functionalities and designing prototype graphical user interface.

\section{A. Prototype Functionalities}

There are six major functions that can be performed by the installed mobile app on the Android device to serve the purpose of managing stress. They are:

1) Sign In and Sign Up Page

2) Check Stress Level Page

3) Meditation Technique Page

4) Relaxing Music Page

5) Progress Tracking Page

6) Reminder Page

\section{B. Prototype Graphical User Interface}

\section{1) Sign In and Sign Up Page}

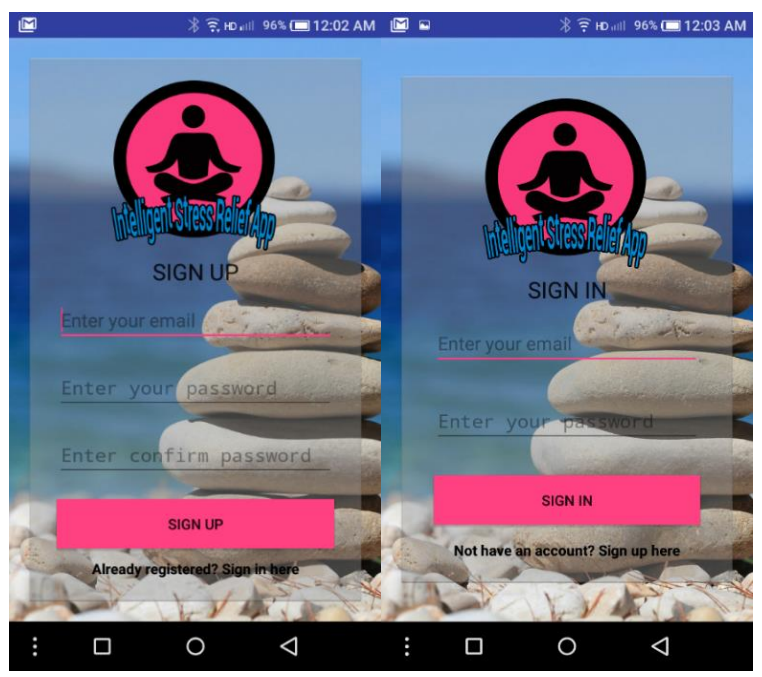

Fig.10. Sign up and Sign in page 
User needs to sign up an account in order to use the proposed mobile app. This will prevent user data from losing when user might be changing to new device or formatting their device. Having a registered account would ease in extracting logs and records of activities. Fig. 10 shows sign up and sign in page of the application.

2) Check Stress Level

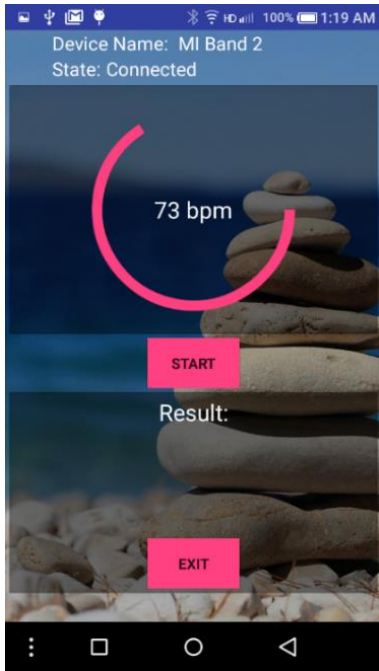

(a)

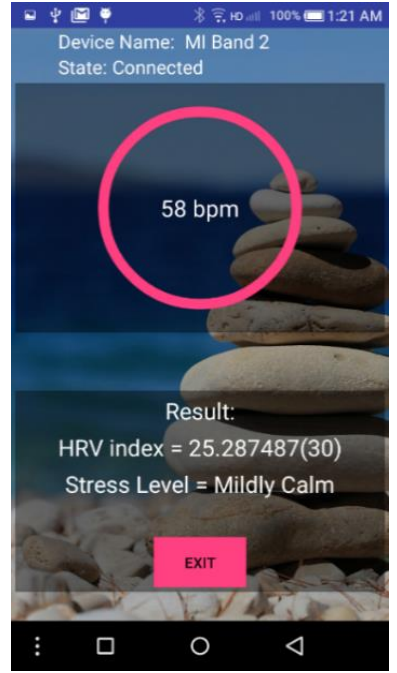

(b)

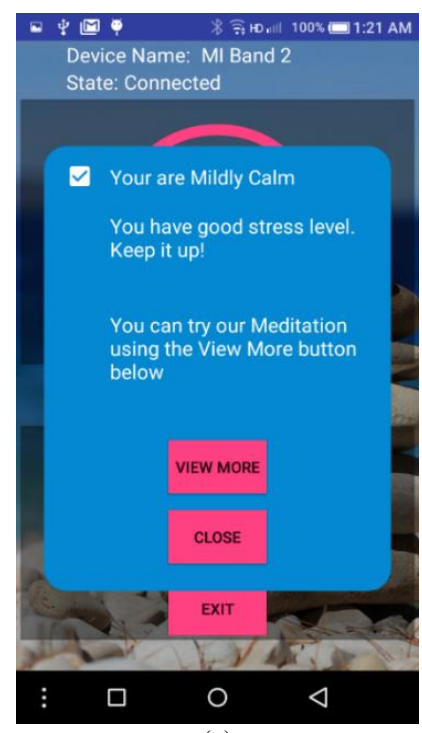

(c)

Fig.11. Check stress level sequence. (a) Scanning heart rate variability; (b) Displaying HRV with stress level; (c) Advice given based on stress level.

Fig. 11 shows the processes of determining stress level. Fig. 11 (a) is the page of scanning user's heart rate variability through the Bluetooth connection from a heart rate sensor. It would take around two to three minutes before getting the HRV result. Moreover, the application will also show live update of user heart rate beats per minute (bpm) information during the stress level checking. Fig. 11(b) shows the result of stress level together with the HRV triangular index at the end of the activity. With the stress level determined, advice of practicing a particular meditation technique is provided to users. Music will also be played based on the various stress levels. From the screen, user can choose to read more about the suggestion given or to close the pop-out message.

\section{3) Meditation Technique Page}

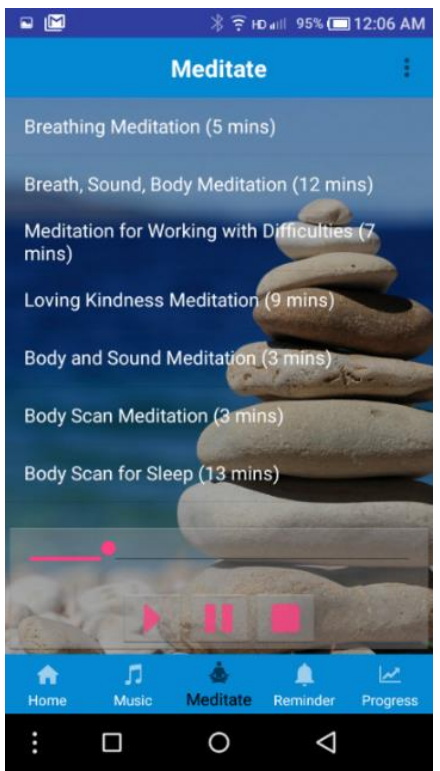

Fig.12. Meditation technique page

Fig. 12 shows the meditation technique page of the application. This is where user can play meditation technique audio for practicing in order to reduce their stress. There are different meditation technique audios to be chosen. Each with different duration of practicing.

4) Relaxing Music Page

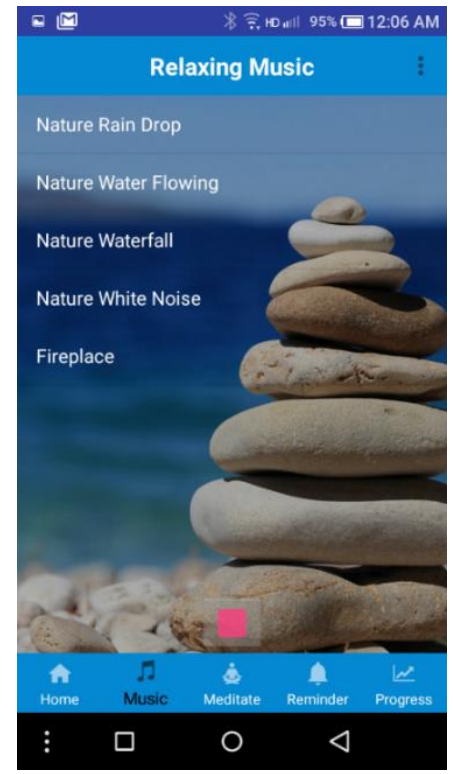

Fig.13. Relaxing music page

Fig. 13 shows the relaxing music page of the application. This is where user can play relaxing music in the event that the user does not like the auto-played music provided along with the stress result. This gives the flexibility for user to have their own preference in playing relaxing music. 
5) Progress Tracking Page

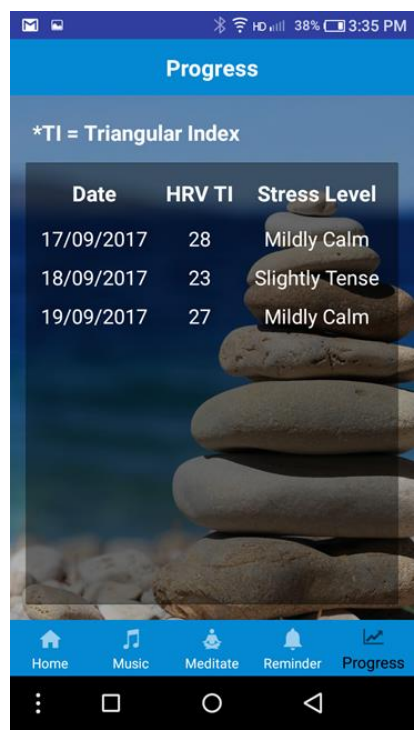

Fig.14. Progress tracking page

Fig. 14 shows the progress page of the proposed application. This is the log page where user can keep track of their stress level results. With the records of daily stress level, user can easily monitor their stress status and equip with better stress management skill.

\section{6) Reminder Page}

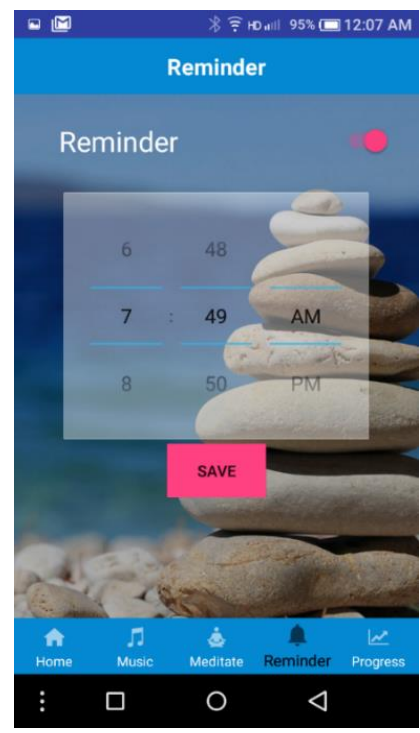

Fig.15. Reminder page

Fig. 15 shows the reminder page of the application. User can set a timer in the proposed application to remind user on checking their stress level. This is essentially important for those who are under stress and needs to have self-monitoring for stress management.

\section{RESULT}

Several software testing are carried out in order to test the validity and reliability of the newly developed application. Unit test is performed on each individual module (feature module) to evaluate whether they fit the intended purpose. After the individual modules pass the unit test, the individual modules are combined and integration test is carried out to evaluate the performance and reliability of the functions. The layout of the graphical user interfaces of the proposed application is tested as well. This is to ensure that the proposed application works well on different phone models.

Table 3 presents the test case scenarios and the results. Different aspects are covered in the test cases to confirm the smoothness and efficiency of the proposed application. The test cases are expected to provide a promising output. If there is error found during testing, the code is continuously debugged and revised until everything is fine.

Table 3. test case scenarios

\begin{tabular}{|c|c|c|}
\hline Test Cases & Expected Output & Result \\
\hline $\begin{array}{l}\text { Turn on Bluetooth } \\
\text { connection }\end{array}$ & Bluetooth enabled & Pass \\
\hline $\begin{array}{l}\text { Turn off Bluetooth } \\
\text { connection }\end{array}$ & Bluetooth disabled & Pass \\
\hline $\begin{array}{c}\text { Scan nearby } \\
\text { Bluetooth devices }\end{array}$ & $\begin{array}{c}\text { Found nearby } \\
\text { Bluetooth devices }\end{array}$ & Pass \\
\hline $\begin{array}{l}\text { Pairing Bluetooth } \\
\text { device }\end{array}$ & $\begin{array}{l}\text { Bluetooth device is } \\
\text { paired successfully }\end{array}$ & Pass \\
\hline $\begin{array}{c}\text { Unable to Pair } \\
\text { Bluetooth Device }\end{array}$ & Pairing failed & Pass \\
\hline $\begin{array}{c}\text { Unpairing with paired } \\
\text { device }\end{array}$ & $\begin{array}{c}\text { Devices are } \\
\text { unpaired }\end{array}$ & Pass \\
\hline $\begin{array}{c}\text { Connect to Bluetooth } \\
\text { device }\end{array}$ & $\begin{array}{l}\text { Bluetooth device is } \\
\text { connected }\end{array}$ & Pass \\
\hline $\begin{array}{c}\text { Unable to connect to } \\
\text { device }\end{array}$ & $\begin{array}{l}\text { Device is not } \\
\text { connected }\end{array}$ & Pass \\
\hline $\begin{array}{c}\text { Disconnecting to } \\
\text { device }\end{array}$ & $\begin{array}{c}\text { Device is } \\
\text { disconnected }\end{array}$ & Pass \\
\hline $\begin{array}{l}\text { Unable to disconnect } \\
\text { with device }\end{array}$ & $\begin{array}{l}\text { Device is not } \\
\text { disconnected }\end{array}$ & Pass \\
\hline $\begin{array}{c}\text { Check stress level } \\
\text { when Bluetooth } \\
\text { device is } \\
\text { disconnected. }\end{array}$ & $\begin{array}{l}\text { Failed to start } \\
\text { checking. }\end{array}$ & Success \\
\hline $\begin{array}{l}\text { Check stress level } \\
\text { when Bluetooth } \\
\text { device is connected. }\end{array}$ & $\begin{array}{l}\text { Start checking } \\
\text { successfully. }\end{array}$ & Success \\
\hline $\begin{array}{c}\text { HRV Triangular } \\
\text { Index is between } 2 \\
\text { and } 15 .\end{array}$ & $\begin{array}{l}\text { Stress level result } \\
\text { is "Highly Tense" }\end{array}$ & Success \\
\hline $\begin{array}{c}\text { HRV Triangular } \\
\text { Index is between } 16 \\
\text { and } 25 .\end{array}$ & $\begin{array}{l}\text { Stress level result } \\
\text { is "Slightly Tense" }\end{array}$ & Success \\
\hline $\begin{array}{c}\text { HRV Triangular } \\
\text { Index is between } 26 \\
\text { and } 52 .\end{array}$ & $\begin{array}{l}\text { Stress level result } \\
\text { is "Mildly Calm" }\end{array}$ & Success \\
\hline
\end{tabular}




\begin{tabular}{|c|c|c|}
\hline $\begin{array}{c}\text { HRV Triangular } \\
\text { Index is between } 53 \\
\text { and } 60 .\end{array}$ & $\begin{array}{l}\text { Stress level result } \\
\text { is "Quietly } \\
\text { Relaxed" }\end{array}$ & Success \\
\hline $\begin{array}{l}\text { HRV Triangular } \\
\text { Index is more than } \\
60 .\end{array}$ & $\begin{array}{l}\text { Stress level result } \\
\text { is "Deeply } \\
\text { Relaxed" }\end{array}$ & Success \\
\hline $\begin{array}{l}\text { Stress level result is } \\
\text { "Quietly Relaxed" }\end{array}$ & $\begin{array}{c}\text { Show compliment } \\
\text { words. }\end{array}$ & Success \\
\hline $\begin{array}{l}\text { Stress level result is } \\
\text { "Deeply Relaxed" }\end{array}$ & $\begin{array}{c}\text { Show compliment } \\
\text { words. }\end{array}$ & Success \\
\hline $\begin{array}{l}\text { Stress level result is } \\
\text { "Mildly Calm" }\end{array}$ & $\begin{array}{c}\text { Show compliment } \\
\text { words. }\end{array}$ & Success \\
\hline $\begin{array}{l}\text { Stress level result is } \\
\text { "Slightly Tense" }\end{array}$ & $\begin{array}{l}\text { Play relaxing } \\
\text { music. }\end{array}$ & Success \\
\hline $\begin{array}{l}\text { Stress level result is } \\
\text { "Highly Tense" }\end{array}$ & $\begin{array}{c}\text { Play relaxing } \\
\text { music and } \\
\text { meditation audio. }\end{array}$ & Success \\
\hline $\begin{array}{l}\text { Click one of the } \\
\text { meditation technique }\end{array}$ & $\begin{array}{c}\text { Particular } \\
\text { meditation } \\
\text { technique audio is } \\
\text { played. }\end{array}$ & Success \\
\hline $\begin{array}{l}\text { Click one of the } \\
\text { relating music }\end{array}$ & $\begin{array}{l}\text { Particular music is } \\
\text { played. }\end{array}$ & Success \\
\hline $\begin{array}{l}\text { Tracking records of } \\
\text { results }\end{array}$ & $\begin{array}{l}\text { List of scanned } \\
\text { results is } \\
\text { displayed. }\end{array}$ & Success \\
\hline $\begin{array}{l}\text { Set reminder for } \\
\text { stress management }\end{array}$ & $\begin{array}{l}\text { Reminder is saved. } \\
\text { Reminder rings at } \\
\text { the preferred time. }\end{array}$ & Success \\
\hline
\end{tabular}

Other than this, a post survey has been conducted to collect the feedback from the user regarding the performance of the prototype of the proposed mobile application. The target audience is any users who own Android devices and Bluetooth heart rate sensors. About 55 users participated the survey. Based on the survey, there are $80 \%$ of the participants have used or downloaded existing Android apps related to stress management that are available in the Google Play Store. In this survey, most of the participants who installed the proposed application agree that the proposed application is user-friendly. $90 \%$ of them are satisfied with the proposed application and would like to continue using the proposed application in their daily life. Besides, $85 \%$ of them think that the proposed application will help them to reduce stress and manage their stress effectively. Most of them would likely recommend the mobile app to their family members, friends and others. Lastly, the feature of the proposed application where the relaxing music and meditation audio will be play automatically based on the specific stress result, has been chosen as the best feature by most of the participants.

\section{CONCLUSION}

An android application named "Intelligent Stress Relief App" is proposed with the aim to assist the users in managing their daily stress in a better way. This proposed application utilizes the technology of Bluetooth to connect the heart rate sensor to the Android device. Heart rate data is obtained from the Bluetooth heart rate sensor and transmitted to the proposed application in the Android device. Knowing stress level is important in order to handle the stress with suitable methods. Most of the time, people do not aware that they are facing mental stress until it becomes worsen. Using the heart rate data, the HRV triangular index is calculated and user is able to know their stress level.

In view of releasing stress, user is able to play relaxing music and meditation audio provided by the proposed application. Many studies shown that listening to relaxing music and meditation audio can indeed reduce stress gradually in time.

Most importantly, user can keep track their daily stress level with the use the proposed application. The logs of the tracked stress level can be a reference for user to maintain their emotion and to monitor the improvement of their own stress level over time. With these, user can plan their activities on improving their stress level and thus having better stress management.

The highlight of the proposed idea is the portability in tracking own stress. Without relying on a static heart rate sensing equipment, the wearable Bluetooth heart rate sensor with the proposed application encourages the users to track their stress anywhere anytime.

There are still chances of improvements or features can be added to the application in the future. One of them is to expand the database of relaxing music and meditation audio. Other than that, the application can be enhanced by minimizing the scanning time in extracting the heart rate data.

\section{REFERENCES}

[1] Health and Safety Executive. (2018). Work-related stress, depression or anxiety. Retrieved from Health and Safety Executive: http://www.hse.gov.uk/statistics/causdis/stress/

[2] AIA Launches Malaysia's Healthiest Workplace by AIA Vitality (2017). Retrieved from Malaysia's Healthiest Workplace by AIA Vitality: https://www.aia.com.my/en/about-aia/media-centre/pressreleases/2017/aia-launches-malaysias-healthiestworkplace-by-aia-vitality.html

[3] The American Institute of Stress (2017). Stress Is Killing You. Retrieved from The American Institute of Stress: https://www.stress.org/stress-is-killing-you

[4] Madhuri, V. J., Mohan, M. R., \& Kaavya, R. (2013). Stress Management Using Artificial Intelligence. 2013 Third International Conference on Advances in Computing and Communications, 54-57. https://doi.org/10.1109/ICACC.2013.97

[5] Calm Inc. (2013). Calm. Retrieved from https://itunes.apple.com/us/app/calm-meditation-to-relaxfocus $/ \mathrm{id} 571800810 ? \mathrm{mt}=8$

[6] Kenkou LLC. (2016). Stress Guide. Retrieved from https://itunes.apple.com/us/app/stressguide/id1 $105883821 ? \mathrm{mt}=8$

[7] Pacifica Labs Inc. (2015). Pacifica. Retrieved from https://itunes.apple.com/us/app/pacifica-anxiety-stressdepression/id922968861? $\mathrm{mt}=8$ 
[8] Headspace Inc. (2012). Headspace. Retrieved from https://itunes.apple.com/us/app/headspace-guidedmeditation/id493145008? $\mathrm{mt}=8$

[9] Gman Labs LLC. (2014). Sattva. Retrieved from https://itunes.apple.com/us/app/sattva-meditation-timertracker/id930904592?mt=8

\section{Authors' Profiles}

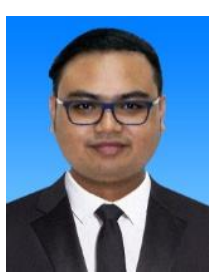

Bukhari Shafiq Bin Asnain: Student of bachelor degree from Faculty of Information Science \& Technology in Multimedia University, majoring in Security Technology. $\mathrm{He}$ is interested towards mobile application developments.

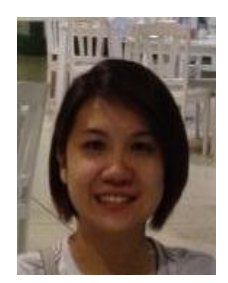

Siew-Chin Chong: received her bachelor's degree in Information Technology, majoring in Software Engineering and the Master degree in Science, majoring Information Technology from Multimedia University in 2003 and 2006 respectively. She is currently a PhD student of Faculty of Information Science \& Technology in Multimedia University. Her research interest includes mobile applications, wireless networking, pattern recognition and distance metrics learning.

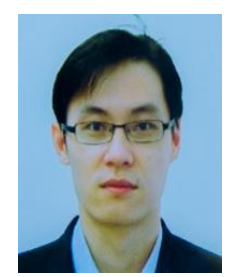

Kuok-Kwee Wee: received his BSc in Computer Science and MSc in Networking from University Putra, Kuala Lumpur, Malaysia. He then completed his study in $\mathrm{PhD}$ (Engineering) from Multimedia University, Malaysia. He is currently Senior Lecturer at the Faculty of Information Science and Technology in Multimedia University, Melaka, Malaysia. He is also a member of Editor Board of an International journal and Senior Member of IEEE. His research interests include quality of service, broadband wireless access, networking and mobile communication.

How to cite this paper: Bukhari Shafiq Bin Asnain, Siew-Chin Chong, Kuok-Kwee Wee, " Human Stress Management through Heart Rate Variability ", International Journal of Image, Graphics and Signal Processing(IJIGSP), Vol.10, No.8, pp. 9-17, 2018.DOI: 10.5815/ijigsp.2018.08.02 